\title{
Development of a new method for eradication of viruses by induction of posttranscriptional gene silencing in transgenic potato plants
}

\author{
A.M. Alexandrova*, O.V. Karpova, R.M. Nargilova, R.V. Kryldakov, B.K. Iskakov \\ M.A. Aitkhozhin Institute of Molecular Biology and Biochemistry, Almaty, Kazakhstan
}

DOI 10.18699/ICG-PlantGen2019-46

(c) Autors, 2019

* e-mail: alena_pisarenko@inbox.ru

\begin{abstract}
A new method of improving potato plants from a viral infection has been proposed. DNA fragments containing the full coding sequence of PVS $25 \mathrm{~K}$ protein in sense and antisense orientations were cloned from $5^{\prime}$ and $3^{\prime}$ ends of intron I of Ricinus communis catalase gene cat1 Ricinus communis into binary agrobacterial vector pCAMBIA2300 under control of $35 \mathrm{~S}$ CaMV promoter and terminator of nopalin synthase gene. Using the recombinant DNA as a transgene, transformation of six varieties of test-tube potato plants, which were infected with PVM, PVS and/or PVY individually or in complex, was carried out. Further field trials of 20172018 allowed us to select four promising transgenic lines that were free from viral infection. Key words: potato virus; PVS; PVM; PVY; RNA-interference; transgene; ELISA.
\end{abstract}

\section{Introduction}

The main focus of potato protection against viral diseases is on the creation of resistant varieties using traditional breeding methods, the recovery of seed material and the protection of planting against reinfection. The existing technologies for obtaining virus-free seed, both using the method of cultivation of apical meristem and using chemo- and heat therapy, as well as cryotherapy, are still expensive and time-consuming and, as a rule, do not eliminate the possibility of secondary infection of plants in the soil. In this regard, potato varieties with genetically fixed resistance to viral diseases are of particular importance. The creation of such varieties by traditional methods of breeding requires decades; moreover, donors of genes for resistance to viral diseases are mostly wild plant species that cannot always be crossed with cultivated varieties using classical methods of selection.

The resistance of transgenic plants to viral infections is considered as a separate type of specific plant resistance (pathogen-derived resistance, PDR). It is known that this kind of resistance is due to the mechanisms of RNA interference (or post-transcriptional gene silencing, PTGS or RNA silencing) and is characterized by highly specific degradation of viral RNA when interacting with transgenic RNA (Simon-Mateo and Garcia, 2011). For this aim, transgenes having a high degree of homology with the nucleotide sequences of the viral gRNA are used.

It was shown that transforming plants containing sense and antisense orientation of the transgene coding sequence, separated by an intron sequence, the so-called "hairpin" structure, is more resistant to viral infection than plants transformed with a vector that carries only a sense or an antisense sequence (Smith et al., 2000; Wesley et al., 2001). The introduction of such "hairpin" structures into cells leads to the formation of double-stranded RNA (dsRNA), which actually trigger the RNA interference mechanism in order to degrade foreign viral RNA in the event of a pathogen penetration (Moissiard and Voinnet, 2004).

Potato viruses $\mathrm{M}$ and S (PVM and PVS) are the most common viruses in Kazakhstan (Loebenstein and Manadilova,
2003; Khassanov, Vologin, 2018; Alexandrova et al., 2018). Until now, no resistance gene donors have been detected for viral diseases caused by these viruses. PVS is a representative of the group Carlaviruses of the family Betaflexiviridae (King et al. 2011). The virus is carried by aphids in a non-persistent manner and infects plants of the families Solanaceae and Chenopodiaceae. Genomic RNA (gRNA) of the virus is represented by positively charged single-stranded mRNA of about 8535 nucleotides in length and has a cap structure at the $5^{\prime}$ end and a poly (A) tail at the $3^{\prime}$ end (Monis et al., 1987; Mackenzie et al., 1989). Six reading frames were found inside the gRNA. ORF1 encodes a polypeptide of $223 \mathrm{~K}$ in size, inside of which are coding sequences of methyltransferase, peptidase, helicase, and RNA-dependent RNA polymerase. ORF2, ORF3 and ORF4 encode $25 \mathrm{~K}, 12 \mathrm{~K}$ and $7 \mathrm{~K}$ proteins that are included in the triple gene block (TGB), characteristic of all Carlaviruses (Morozov et al., 1989; Matoušek et al., 2005). These proteins are responsible for the spread of the virus from one cell to the next and have a region of significant homology with the sequences of the representatives of the potexvirus group. ORF5 encodes a $34 \mathrm{~K}$ coat protein $(\mathrm{CP})$, and ORF6 encodes a cysteine-rich $11 \mathrm{~K}$ protein, which has RNA-binding activity.

A method for the eradication of viral material was proposed in the framework of this study, based on the use of source material infected with one or more viruses to create transgenic potato plants capable of expressing a "hairpin" structure with the coding sequence of the PVS $25 \mathrm{~K}$ protein.

\section{Materials and methods}

The 35S CaMV promoter and terminator of the nopaline synthase gene (nos) were cloned from transient expression vector pBI221 (NCBI GenBank acc. No: AF501128) into binary agrobacterial vector pCAMBIA 2300 (NCBI GenBank acc. No: AF234315) between HindIII and BamHI, SacI and EcoRI, respectively.

The coding sequence of the PVS $25 \mathrm{~K}$ protein in two orientations (sense and antisense) was inserted into secondary plasmid vector pRAJ17 created on the basis of pBluescriptII 
$\mathrm{KS}+$ and containing intron 1 of the I catalase cat1 Ricinus communis catalase gene catl between the BamHI / NcoI and SalI / SacI restriction sites. The following primers were selected for cloning the coding sequence of $25 \mathrm{~K}$ protein in sense (\# 306 and \# 308) or into antisense orientation (\# 307 and \# 309) (the restriction sites are underlined, restrictase names are shown to the right):

\#306 5'- cgtaggatcc ttaggeggeg tgtaagtgg -3' NcoI

\#307 5'- cgtagagctc atgaggatat ttgatagctt $-3^{\prime} \quad$ SacI

\#308 5'- cgtaggatcc atgaggatat ttgatagctt $-3^{\prime} \quad$ Bam HI

\#309 5'- cgtagtcgac ttaggcggcg gtgtaagtgg -3' SalI

The sense or antisense sequences of the $25 \mathrm{~K}$ protein cloned into pRAJ17 using BamHI and NcoI (located on the 5' end of the intron) or SalI и SacI (on 3' end of the intron). Then the DNA fragment from Bam HI and $\mathrm{SacI}$ was recloned into pCAMBIA 2300 with the $35 \mathrm{~S}$ CaMV promoter and the nos-terminator. As a result, recombinant DNA with the [35S CaMV - 25K Sense - intron - 25K Asense - nos] cassette was created (Figure 1).

Potato plant transformation was carried out according to a standard method (Raldugina et al., 2011). DNA and RNA from transgenic plant leaves were isolated by a standard method using Trizol according to the manufacturer's recommendations (Sigma). Amplification of DNA fragments was performed using Pwo polymerase (Roche) according to the manufacturer's method. The program for amplification: stage 1: $5 \mathrm{~min}$ at $94{ }^{\circ} \mathrm{C}, 1$ cycle; stage 2: $30 \mathrm{sec}$ at $94{ }^{\circ} \mathrm{C}$, $30 \mathrm{sec}$ at $54^{\circ} \mathrm{C}, 1 \mathrm{~min} 30$ seconds at $72^{\circ} \mathrm{C}, 30$ cycles; stage 3 : 5 min at $72^{\circ} \mathrm{C}, 1$ cycle. The presence of PVS, PVM and PVY infection was determined by the standard DAS-ELISA method using commercial kits from BIOREBA as recommended by the manufacturer. The measurements were carried out on a Stat Fax 2100 photometer (Awareness) at $405 \mathrm{~nm}$.

\section{Results and discussion}

The presence of the $25 \mathrm{~K}$ protein is characteristic of all Carlaviruses, its coding sequence is known as part of the TGB. The property of the PVM $25 \mathrm{~K}$ protein is its ability to suppress RNA silencing (Senshu et al., 2011). In this study, DNA fragments containing the full coding sequence of the PVS $25 \mathrm{~K}$ protein were cloned from the 5' and 3' ends relative to the intron I of the Ricinus communis catalase gene cat 1 in the sense (Sense) and antisense (Asense) orientations into binary agrobacterial vector pCAMBIA 2300 under the control of the 35S CaMV promoter and the nos-terminator (Figure 1).

Potato plants of the varieties 'Dunyasha', 'Zeren', 'Kormilitsa', 'Albinka', 'Fortune', 'Picasso', 'Santa', 'Tien-Shansky' and 'Tokhtar' which were free from viral infection or infected with PVM, PVS and/or PVY alone or in complex were transformed by cocultivation with agrobacteria carrying the created recombinant DNA. The transformation efficiency for each variety was evaluated by the number of the regenerants containing the transgene (Table 1). Normal shoots were obtained only in 'Albinka', 'Dunyasha', 'Zeren' and 'Kormilitsa' after regeneration and transformation.

The plants were analyzed for the presence of recombinant DNA constructs, as well as RNA transcripts corresponding to the transgene. Transgenic plants that showed a positive response during these analyses were grown in soil and fur- ther tested for the presence of viruses using the DAS-ELISA method. According to our observations, a decrease in ELISA readings from a high value at the moment of planting into the soil to fewer readings during the first six months of observations was caused not only by the successful triggered RNA interference in cells during further plant development after transformation, but also by laboratory manipulations. The viruses did not have time to accumulate in the shoots of tubetest plants during grafting when the continuous intensive apical growth occurred. Therefore, there was a decrease in ELISA values even in untransformed plant regenerants which was observed, for example, for 'Zeren' and 'Dunyasha' infected with PVM. However, samples of these plants taken later again revealed the presence of viral infection after growing for two months in the soil in the greenhouse. That was the reason for the prolonged observation of the lines that had gone through the eradication procedure.

It was also noted that the original 'Zeren' plants which initially carried PVM + PVS + PVY infection had no more PVM during field trials, although this variety gave a positive response to the presence of this virus during the first six months after transformation. As a rule, several viruses in one plant can coexist if they belong to different groups. Moreover, if the titer of a more virulent pathogen remains at the same level, the titer of a less virulent pathogen grows during the growing season of the plant (Nyalugwe et al., 2012; Hameed et al., 2014). The results presented here are not consistent with the previous findings.

The enzyme immunoassay was performed every 30 days for 6 months after the transfer of transgenic plants to the soil in the greenhouse. Transgenic lines TL-59, TL-44, TL-62, TL-65 and all 'Albinka' lines had no changes and were infected by PVM and PVY as before transformation. As for the other varieties, there were lines that showed a decrease in ELISA value up to the complete absence of a positive response. As a result, the 4 transgenic lines were selected as being free of virus. TL-61 and TL-67 ('Dunyasha'), as well as TL-103 ('Kormilitsa') infected with PVM before transformation had a negative response. Moreover, complex infection with PVM + PVS + PVY was eliminated in TL-119 ('Zeren').

In 2017 and 2018, microtubers of 14 transgenic lines TL-39, TL-43, TL-46, TL-48, TL-74 and TL-159 ('Albinka'), TL-59 and TL-119 ('Zeren'), TL-44, TL-61, TL-62, TL-65, TL-67 ('Dunyasha') and TL-103 ('Kormilitsa') were planted in the field. Besides transgenic plants, the plants infected by different viruses (Table 1) and control virus-free plants of the same varieties were also grown to create a viral background and to check the rates of virus contamination. The presence of PVM, PVS and/or PVY had already been seen in virus-free control plants after the first ELISA in 2017.

During each season, leaf samples were collected from each plant three times for ELISA 1, 2 and 3 months after planting. Lines TL-103, TL-44, TL-61 and TL-67 remained free of PVM. PVM, PVS and PVY were eliminated in TL-119 plants.

Virus-free tubers were used for planting in 2018. After ELISA analysis, PVM and PVS were not detected in TL-103 and TL-119. PVM was not found in TL-61 and TL-67. TL-119 showed eradication of three viruses after the first six months 


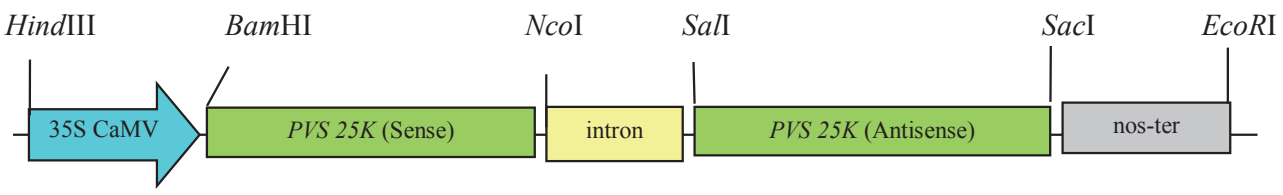

Figure 1. Scheme of the recombinant DNA cassette created as part of agrobacterial plasmid vector pCAMBIA2300 and used as a transgene for potato plant transformation.

\section{Table 1}

Transformation efficiency of various potato varieties

\begin{tabular}{lllll}
\hline Name of varieties & Virus infection & Number of regenerants (units) & Number of transgenic shoots (units) & Transformation efficiency, \% \\
\hline 'Albinka' & PVM, PVY & 18 & 8 & 44.4 \\
'Dunyasha' & PVM & 13 & 5 & 38.5 \\
'Zeren' & PVM, PVS, PVY & 15 & 4 & 26.7 \\
'Kormilitsa' & PVM & 5 & 1 & 20.0 \\
'Picasso' & PVM, PVY & 0 & 0 & 0 \\
'Santa' & PVM, PVY & 0 & 0 & 0 \\
'Tokhtar' & PVM & 0 & 0 & 0 \\
'Tien-Shansky' & PVM & 1 & 0 & 0 \\
'Fortune' & PVM, PVS & 0 & 0 & 0 \\
\hline
\end{tabular}

in the greenhouse. However, during field trials, a positive response to PVY was shown in 2017 by one out of five plants planted and in 2018 by seven out of 9 plants planted. PVY belongs to Potyvirus, PVS and PVM are Carlaviruses. The recombinant DNA construct developed was directed against PVS, but in the case of PVM it could be a trigger of RNA interference due to homology between genomic sequences. Although the amino acid sequences of the $25 \mathrm{~K}$ proteins of PVS, PVM and PVX have more differences than capsid proteins, conservative domains about 20 amino acids in size were found at the $\mathrm{N}$-terminus of these proteins.

\section{Conclusion}

The problem of multiple infections in potato fields in Kazakhstan still persists. A new methods of treatment of plants infected with related and unrelated viruses is proposed with the example of a transgene carrying the complete coding sequence of the PVS $25 \mathrm{~K}$ protein in two orientations and able to induce RNA interference in plant cells. As a result, four virus-free lines were obtained. Thus, it has been proven that the coding sequence of the PVS $25 \mathrm{~K}$ protein is a good target for the action of RNA interference.

\section{References}

Alexandrova A.M., Karpova O.V., Nargilova R.M., Kryldakov R.V., Nizkorodova A.S., Zhigaylov A.V., Yekaterinskaya E.M., Kushnarenko S.V., Akbergenov R.Zh., Iskakov B.K. Distribution of potato (Solanum tuberosum) viruses in Kazakhstan. Internetional Journal Biology Chemistry. 2018;11(1):33-40.

Hameed A., Iqbal Z., Asad S., Mansoor S. Detection of multiple potato viruses in field suggests synergistic interactions among potato viruses in Pakistan. Plant Pathol. J. 2014;30(4):407-415. DOI 10.5423/PPJ.OA.05.2014.0039.

Khassanov V.T., Vologin S.G. Occurrence of the Ordinary and the Andean Strains of Potato Virus S Infecting Potatoes in the Eastern Region of Kazakhstan. Plant Disease. 2018;102(10):2052. DOI 10.1094/PDIS-12-17-2000-PDN.

King A., Lefkowitz E., Adams M.J. Virus Taxonomy. Ninth Report of the Intern. Committee on Taxonomy of Viruses. Elsevier, 2011.
Loebenstein G. and Manadilova A. Virus and virus-like diseases of major crops in developing countries. Springer, Dordrecht, Netherlands. 2003:195-200. DOI 10.1007/978-94-007-0791-7 8.

Mackenzie D., Tremaine J., Stace-Smith R. Organisation and interviral homologies of 3'-terminal portion of potato virus RNA. J. Gen. Virol. 1989;70:1053-1063. DOI 10.1099/0022-1317-70-5-1053.

Matoušek J., Schubert J., Ptaček J., Kozlova P., Dedič P. Complete nucleotide sequence and molecular probing of potato virus $\mathrm{S}$ genome. Acta virologica. 2005;49:195-205.

Moissiard G., Voinnet O. Viral suppression of RNA silencing in plants. Molecular Plant Pathology. 2004;5:71-82.

Monis J., Daniels S., De Zoeten G., Slack S. Characterization of potato virus S (PVS) genomic RNA. Phytopathol. 1987;77:1742.

Morozov S., Dolja V., Atabekov J. Probable reassortment of genomic elements among elongated RNS-containing plant viruses. J. Mol. Evol. 1989;29:52-62.

Nyalugwe E., Wilson C., Coutts B., Jones R. Biological properties of Potato virus $\mathrm{X}$ in potato: effect of mixed infection with Potato virus $\mathrm{S}$ and resistance phenotypes in cultivars from three continents. Plant Disease. 2012;96(1):43-54. DOI 10.1094/PDIS-04-11-0305

Raldugina G., Danilova S., Yurjeva N. Molecular-genetic and biochemical methods of modern plant biology. Binom. Laboratory of knowledge. 2011;13-24. https://www.rfbr.ru/rffi/ru/books/o 1781847\#3

Senshu H., Yamaji Y., Minato N., Shiraishi T., Maejima K., Hashimoto M., Miura C., Nerya Y., Namba S. A dual strategy for the suppression of host antiviral silencing: two distinct suppressors for viral replication and viral movement encoded by Potato virus M. J. Virol. 2011;85(19):10269-10278. DOI 10.1128/JVI.05273-11.

Smith N.A., Singh S.P., Wang M.-B., Stoutjesdijk P.A., Green A.G., Waterhouse P.M. Total silencing by intron-spliced hairpin RNAs. Nature. 2000;407:319-320.

Simon-Mateo C., Garcia J.A. Antiviral strategies in plants based on RNA silencing. Biochim Biophys Acta. 2011;1809(11-12):722-731. DOI 10.1016/j.bbagrm.2011.05.011

Wesley S., Helliwell C., Smith N., Wang M., Rouse D., Liu Q., Gooding P., Singh S., Abbott D., Stoutjesdijk P., Robinson S., Gleave A., Green A, Waterhouse P. Construct design for efficient, effective and high-throughput gene silencing in plants. Plant J. 2001;462-469.

Acknowledgements. This research was supported by grant AP05131133 (2018-2020) of Ministry of Education and Science, Republic of Kazakhstan.

Conflict of interest. The authors declare no conflict of interest. 